\title{
Getting personal with marketing research: A first year teaching innovation. A Practice Report
}

\author{
Mary FitzPatrick and Janet Davey \\ Department of Marketing \\ University of Waikato \\ Monica van Oostrom \\ Waikato Management School \\ University of Waikato
}

\begin{abstract}
"Research" can be a challenging topic for lecturers to teach, and a dry subject for students to learn. This paper presents a teaching innovation that involves first year students personally in the topic of marketing research - both as participant/producers of the research data and as clients/end-users of the marketing research. The teaching/learning innovation is based on pedagogical principles to make research theory accessible by bringing marketing research to life. It begins with personal data produced by the students, which is collated and then presented in the lectures, overlaid on a collage of the students' ID photos to make the innovation visually engaging and to illustrate a real-life application of the marketing research process. For the students, this application that describes their own behaviours and opinions is immediately relevant. For us as teachers it is an exciting teaching activity that simultaneously demonstrates the practice, benefits, and processes of marketing research.
\end{abstract}

\section{Please cite this practice report as:}

FitzPatrick, M., Davey, J. \& van Oostrom. (2010). Getting personal with marketing research: A first year teaching innovation. A Practice Report. The International Journal of the First Year in Higher Education, 1(1), 84-90.

This practice report has been accepted for publication in Int J FYHE. Please see the Editorial Policies under the 'About' section of the Journal for further information.

(C) Copyright of practice reports is retained by the author/s. As an open access journal, practice reports are free to use, with proper attribution, in educational and other non-commercial settings. ISSN: $1838-2959$ 


\section{Introduction}

Despite the importance of inquiry skills for basic survival in today's complex, fluid, contested world, university research courses continue to cause much eye-rolling and groaning among both students and lecturers. University students at all levels and across a range of disciplines increasingly are required to understand, handle, interpret, as well as produce research-based information. However, while universities invest considerable resources in the teaching of research in general, student learning outcomes typically are disappointing and the students frequently consider research to be one of the most difficult subjects in their studies (Murtonen \& Lehtinen, 2005). Teaching research can become especially challenging in the context of a large introductory class, when a significant number of students can feel unconfident, depersonalized, and isolated from their teachers and fellow students (e.g., Bath, 2009; Krause, 2005). This paper presents a teaching innovation that has been developed to teach research in an introductory marketing course of approximately 350 students from a range of cultural and educational backgrounds. The challenge for us as teachers at this first year level is to teach research in a way that engages students and thus "sets up" marketing research as an interesting subject upon which teachers can build interest and knowledge in later courses.

Within the discipline of marketing, marketing research is regarded as a foundation topic in marketing education and a crucial component of marketing practice. Many marketing lecturers, however, privately regard marketing research as a decidedly dry and boring "poor cousin" in comparison to stimulating topics such as marketing promotion and communication. Not surprisingly, marketing research also tends to be one of those topics that our students love to hate. Taking a marketing perspective, understanding the students - the consumers in this service context - is fundamental to addressing the challenge of teaching research and making the subject a more attractive curriculum offering to student consumers (Evans, Jamal, \& Foxall, 2006; Solomon, Bamossy, \& Askegaard, 2002). From this standpoint, to be of "value" to our consumers - the students - the teaching of research must be personal, relevant, and individualised (see Holbrook, 1999; Smart, Kelley, \& Conant, 1999).

Pedagogical pointers In the context of higher education, the scholarship of learning and teaching offers important insights into learner behaviour and a sound base for teachers to develop teaching/learning activities that will be a better fit with student-consumers. The deep, meaningful, and active learning about research that we want for our students has its corollaries in established teaching practices founded on principles such as inquiry-based teaching and experiential learning activities, as well as particular concepts such as personalisation and meaningfulness.

The inquiry-based teaching approach supports setting up learning opportunities that encourage research-minded responses from students as a way of teaching them to be enquiring or research oriented in their approach to life and fostering "intellectual flexibility, analysis and enquiry" (Hammond, 2007, p. 3). Based on studies of research-teaching linkages, the inquiry - or research — mode of teaching urges teachers to involve the students in the learning process as co-researchers. Following this approach, students should be introduced progressively to inquiry as a mode of learning and ideally engaged as participants rather than as audience, right from the start of their tertiary study.

Experiential learning is another contemporary learning approach used in a range of contemporary marketing education contexts (see Bobbitt, Inks, Kemp \& Mayo, 2000; Bridges, 1999; Hamer, 2000). In its most general sense, experiential learning involves learners in activities in which they construct knowledge through understanding and 
transforming experience (Kolb \& Kolb, 2009). Learners construct their knowledge through experiences engineered by teachers, in what Clarke refers to as "the 'doing' of the tasks" (2008, p. 54). Kolb and Kolb (2009), in their description of the experiential learning process as a cycle that is driven by the resolution of the dual tensions between action/reflection and experience/abstraction, underscore the important links between "doing" and thinking in experiential learning that we are aiming for in our first year students.

Finally, the concepts of personalisation and meaningfulness also inform this teaching innovation. A multi-faceted concept, "personalisation" emphasises the student as an individual member of a learning community in order to ensure retention, engage and empower students, and increase their motivation and self-confidence. This personalisation is particularly essential at the outset, in the first year of higher education study (Knox \& Wyper, 2008). Educationalists also regard the "meaningfulness" of new material and/or learning experiences to students to be an important consideration in educational success (Moon, 2004). When such material or activities are perceived by the learner to be meaningful, students are better able to make the strong cognitive connections required to deepen their understanding and transform knowledge. The concept supports teachers" efforts to "set up" learning experiences in such a way that learners can relate new material easily to their existing knowledge, thus underlining the need to be mindful of building on what is already known to students.

\section{The teaching innovation}

The challenge we set ourselves was how we could best engage the large, diverse class of first year university students with the basic principles and process of marketing research. Based on the literature, we realised that in order to be engaging from the students' perspective, the teaching application had to be meaningful, current, believable, coherent, and connected. From a chance conversation about using students as survey subjects, we have developed (and continue to refine) an innovative application, called the Class Snapshot: First Year Marketing Students, in which the students step into the marketing research process as research participants to generate data that is "the ultimate" in meaningfulness, immediacy, and authenticity simply because it all about them. Finally, to ensure coherence, we designed the application to last the distance through the seven-step marketing research process outlined in the course textbook, as opposed to disjointed one-off examples for each separate step, such as those presented in the textbook. It is nothing new to call for the use of real data in courses in order to connect theory with practice and actively engage the students in the learning experience. Our innovation is to personally involve first year marketing students on several levels, as both participant/producers of the research data and clients/end-users of the marketing research information presented to them in the classroom. In the following section, we describe the application and its implementation in detail.

Ten days before we begin teaching the Marketing Research topic, the students are invited to complete an online questionnaire comprising 53 questions. The data generated by the students is analysed using Microsoft Excel. Then, in the Marketing Research lectures, we use the data produced by the students to illustrate each of the seven steps in the marketing research process as outlined in the textbook (1. Define the research problem; 2. Determine the research design; 3 . Choose the method for collecting primary data; 4 . Design the sample; 5. Collect the data; 6. Analyse and interpret the data; 7. Prepare the research report). At that point when we present their data to them in class, the students effectively become the "clients" to whom the research report is made. For each of the seven steps, we present key 
points (concepts, procedures, etc) that relate to a specific stage, then follow immediately with Class Snapshot slides that illustrate how that step applies to their research data. In this way, the Class Snapshot links the students' data directly to the relevant concepts and procedures for each step. For example, in Step 3 of the process, Choose the method for collecting primary data, we talk about the different methods for collecting data (e.g., telephone surveys, face-to-face interviews, mail questionnaires, online questionnaires, personal observation, mechanical observation, etc.) and discuss the advantages and disadvantages of each. We follow these "content" slides with Class Snapshot slides that identify their research method as a structured, online questionnaire, with advantages for the participants of anonymity and convenience, which at the same time enables the researchers to design a relatively lengthy questionnaire (53 questions) and achieve a reasonably high response rate. At Step 6: Analyse the Data, one of our computer support staff comes in to demonstrate how the student data is analysed using Excel and then shows how their research data can be best displayed using various graphical representations (e.g., bar graphs compared to line graphs or pie charts).

The lecture slides on which we present the students' marketing research are designed deliberately to look quite different from the content slides. The first slide that introduces the Class Snapshot application is covered with headshots of the students in the class. This visually brings the individual students together into a class "community." We digitally fade this collage of student photos and use it as the background of the following Class Snapshot slides, upon which the students' research data is displayed on the foreground. As a visual device, the collage of students' faces signals the actual application of research theory to these real-life consumers. The headshots help keep the application personalised and meaningfulas the collage comes up at each step throughout the Marketing Research process, the students are able to re-engage quickly on a personal, visual level with the application. In this way, the headshots visually add an extra layer of meaningfulness to the research data that describes the students' own behaviours and opinions. Finally, the headshots are an interesting, symbolic reminder that the aggregated statistical data gathered from this community of learners is compiled on the behaviour of individuals.

For us as teachers, by the end of the Class Snapshot activity we understand our studentconsumers better because we know some of their important lifestyle characteristics and values. This is valuable information for ensuring other teaching activities and examples used throughout the course are also engaging. For the students, this application exercise makes marketing research personal on all sorts of levels - they have experienced filling in the questionnaire, they have shared the experience as a community of inquiry of taking part in the survey, they learn as both participants and clients about themselves as a consumer population, and they see their own data transformed into meaningful and useful marketing information. We have used the innovation three times now, each time tweaked to improve it. It has felt "right" to us each time we used it - our intuitive sense of success fuelled by the buzz in the lecture theatre, from the time the first slide goes up and the students recognise themselves in the Big Picture, to enthusiastically taking in the translation of their data into marketing information.

\section{Reflections on practice}

As marketing educators, we challenged ourselves to increase the relevancy and value of marketing research within the first year marketing course. We supported the Class Snapshot initiative on principles of inquiry-based teaching and experiential learning, as well as on the concepts of personalisation and meaningfulness. From a teaching perspective, the Class Snapshot is a success: it brings the marketing research topic to life, it is exciting to use, plus it 
is pedagogically sound. Each time we have used Class Snapshot we have refined it on the basis of feedback from the students and new ideas that occur to us when we reflect and debrief. The last time we used Class Snapshot, for instance, we asked the students themselves to identify which of their psychographic characteristics they would like to explore using cross tabulations. Making the decision to test specific relationships such as the correlation between gender and "I am moody"/"I am a slacker," or gender and the importance of "Studying"/importance of "Clubbing" added more depth to students' involvement. They were acting as clients commissioning the data they wanted; at the same time, the students were actively involved as researchers in the data analysis stage of the marketing research process. Other future improvements we are considering include presenting the data as a composite Class Profile (as well as displaying it in simple graphs); adding qualitative questions to the online questionnaire; having the students analyse subsets of the data as part of their tutorial programme; discussing issues of representation and depersonalisation in the quantitative aggregation of data sets. We could also extend the students' experience by displaying some of the student data using more sophisticated 3D graphs, similar to those used by marketing research firms presenting research findings to clients.

\section{Recent research on student evaluations of Class Snapshot}

Results from a survey on students' evaluations of Class Snapshot indicate that the learning, relevance, and personalisation attributes are significant. In the survey, which consisted of five statements using a Likert scale ( $1=$ strongly disagree, $5=$ strongly agree), students rated all statements significantly higher than the test value of $3(n=218, p<.001)$. The statements "It helped me to learn" and "Was relevant to me as a student" had the highest mean rating on the five point scale. There were no significant differences between male and female students although the males rated the personal element ("Was personal to me as an individual") higher than the females. This finding warrants more investigation to explore whether "first year" issues like isolation, meaningfulness, and personalisation might be experienced differently by male and female students. The student evaluations suggest that they appreciated Class Snapshot for its instrumentality in helping them to learn the content of marketing research, through its high relevance and meaningfulness to them as students.

\section{Outcomes of the discussion: Uptake and applications}

The Class Snapshot innovation could be adapted for use by other first-year teachers facing the challenge of taking their students through discipline-specific processes that are fundamental to their discipline but trigger mass eye-rolling in the classroom. At the recent $13^{\text {th }}$ Pacific Rim First Year in Higher Education Conference in Adelaide, Australia, first-year teachers from a range of disciplines in discussing this innovation suggested that rather than using headshots, students could represent themselves using symbols (e.g., maths students choosing a mathematical symbol), objects (e.g., a favourite possession), or fictional characters (e.g., one of the Avatar characters). Another exciting suggestion was to incorporate mobile technology into Class Snapshot by having each student take a short video on their mobile phone to illustrate one of the items on the online questionnaire. For example, a male student could choose to video-record "The importance of shopping" to him personally; another might choose to video-represent "The importance of family." Attaching their video clip would signal that the online questionnaire was complete. These video clips would introduce the students to qualitative research methods and provide a collection of meaningful real-life resources that the teacher could draw on throughout the course to illustrate other key concepts or principles. Student clips on shopping, for instance, could be used in lectures on 
consumer behaviour to illustrate the influence of personality traits (e.g., materialism, self confidence, sociability) or of gender on shopping behaviour. Another suggestion is that, rather than completing the questionnaire online, students could use classroom clickers or their mobile phones to respond to questionnaire items.

\section{Conclusion}

Class Snapshot is a flexible inquiry-based experiential learning initiative, which makes the marketing research topic meaningful by personalising it. We believe that the Class Snapshot innovation helps to spark student enthusiasm for marketing research. Its simplicity means that we have been able to refine and improve it for using in our first year marketing classroom. We are confident that Class Snapshot could be usefully applied by other first-year teachers as a means of building a general sense of community in their classrooms, familiarising their students with research-based information, as well as gauging the opinions of students on specific issues and/or illustrating processes of importance to their discipline.

\section{References}

Bath, D. (2008, June-July). "Do red apples differ from green apples?": Using researchbased learning to facilitate learning and engagement in a large first year course. Paper presented at the $11^{\text {th }}$ Pacific Rim First Year in Higher Education Conference, "An Apple for the Learner: Celebrating the First Year Experience." Hobart, Australia.

Bobbitt, L. M., Inks, S. A., Kemp, K. J., \& Mayo, D. L. (2000). Integrating marketing courses to enhance team-based experiential learning. Journal of Marketing Education, 22(1), $15-25$.

Bridges, E. (1999). Experiential learning and customer needs in the undergraduate market research course. Journal of Marketing Education, 21(1), 51-59.

Clarke, B. (2008). Case and experiential learning methods. Marketing Education Review, 18(2), 54.

Evans, M., Jamal, A., \& Foxall, G. (2006). Consumer behaviour. Chichester, UK: John Wiley $\&$ Sons, Ltd.

Hamer, L. O. (2000). The additive effects of semistructured classroom activities on student learning: An application of classroom-based experiential learning techniques. Journal of Marketing Education, 22(1), 25-34.

Hammond, N. (2007). Preface: Plutarch's fire. In A. Jenkins, M. Healey \& R. Zetter (Eds.), Linking teaching and research in disciplines and departments (pp 3-4). York, UK: The Higher Education Academy.

Holbrook, M. B. (Ed.). (1999). Consumer value: A framework for analysis and research. London: Routledge.

Knox, H. \& Wyper, J. (2008). Quality enhancement themes: The first year experience. Glasgow, UK: Quality Assurance Agency for Higher Education.

Kolb, A. Y. \& Kolb, D. A., (2009). Experiential learning theory: A dynamic, holistic approach to management learning, education and development. In S. C. Armstrong \& C. Fukami (Eds.), Handbook of management education, learning and development (pp. 42-68). London: SAGE.

Krause, K.-L. (2005). Understanding and promoting student engagement in university learning communities. Paper presented at James Cook University Symposium, Townsville/Cairns, Australia.

Moon, J. A. (2004). A handbook of reflective and experiential learning. London: Routledge Falmer. 
Murtonen, M. \& Lehtinen, E. (2005). Conceptions of research and methodology learning. Scandinavian Journal of Educational Research, 49(3), 217-224.

Smart, D. T., Kelley, C. A., \& Conant, J. S. (1999). Marketing education in the year 2000: Changes observed and challenges anticipated. Journal of Marketing Education, 21(3), 217-231.

Solomon, M., Bamossy, G., \& Askegaard, S. (2002). Consumer behaviour: European perspective. London: Prentice Hall. 